\title{
A Worksite Occupational Health Clinic-Based Diabetes Mellitus Management Program
}

\author{
Wayne N. Burton, MD, ${ }^{1,2}$ Chin-Yu Chen, $\mathrm{PhD},{ }^{3}$ Xingquan Li, MS, ${ }^{3}$ Denise Erickson, RN, \\ Maureen McCluskey, $\mathrm{RN}^{2}$ and Alyssa Schultz, $\mathrm{PhD}^{3}$
}

\begin{abstract}
This study is an analysis of a workplace diabetes management program offered to employees of a Fortune 100 financial services corporation located in the United States. The 12-month worksite-based educational program was for employees who were at risk for diabetes, had prediabetes, or were diagnosed with diabetes. This employed population, with health benefits, generally had acceptable control of their diabetes at the start of the program. They statistically improved most self-efficacy measures, but improvement in biometric tests at 6 and 12 months were not significantly different from baseline. Mean hemoglobin A1c at baseline, 6 months, and 12 months was $7.2 \%, 7.2 \%$, and $7.3 \%$, respectively. At 12 months, about $40 \%$ of preprogram survey participants completed all screenings and the post-program questionnaire. Disease management programs at the workplace can be an important component in helping employees enhance their knowledge of diabetes and maintain and improve their health. (Population Health Management 2015;18:429-436)
\end{abstract}

\section{Introduction}

D IABETES MELlitus (DM) affects an estimated 25.8 million Americans or about $8.3 \%$ of the US population. ${ }^{1}$ About 1.9 million Americans aged 20 years or older were newly diagnosed with diabetes in 2011. Another 35\% of adults in the United States aged 20 years or older had prediabetes. As a result, an estimated 79 million Americans age 20 and older have prediabetes. Diabetes affects the working age population with an estimated diagnosed and undiagnosed diabetic population of $3.7 \%$ aged $20-44$ and $13.7 \%$ aged $45-$ 64 . The estimated direct and indirect costs of diabetes in the United States were $\$ 174$ billion, including $\$ 116$ billion in direct costs and $\$ 58$ billion in indirect costs for disability, work lost, and premature mortality (in 2007 dollars). A reanalysis of data estimated that the burden of diabetes and prediabetes was $\$ 218$ billion in 2007 including $\$ 153$ billion in medical costs and $\$ 65$ billion in lost productivity. ${ }^{2,3}$

It is projected that the prevalence of diabetes will increase another 64\% between 2010 and 2025, in large part attributable to the epidemic of obesity in the United States. ${ }^{4,5}$ This is hypothesized to result in 53 million people with diabetes and annual medical and productivity costs of $\$ 500$ billion. Therefore, because diabetes is affecting a growing number of working-age adults, a new role for worksite occupational medicine clinics is disease management of chronic medical conditions such as diabetes. 6,7
A number of studies have generally demonstrated the value of lifestyle interventions in the prevention and management of diabetes. ${ }^{8,9}$ An exception is one study of a lifestyle intervention that focused on weight loss in people with diabetes that showed no reduced risk of cardiovascular disease in overweight and obese persons for these people. ${ }^{10}$

Diabetes self-management education is recommended for all people with prediabetes and diabetes. Such education can lead to the prevention or at least the delayed onset of diabetes and a reduction in the risk of complications from diabetes. National guidelines have been established for selfmanagement education for people with diabetes. ${ }^{11}$ Nevertheless, studies have shown that the majority of people with diabetes and prediabetes do not receive formal diabetes education. ${ }^{12,13}$ There have been very few reports of worksite-based diabetes management programs. ${ }^{14,15}$ The current study documents the effort of a worksite diabetes education program and its initial outcomes, which include comparison of preprogram and post-program surveys as well as results from baseline, 6-month, and 12-month biometric screenings.

\section{Methods}

\section{Study population}

This is a prospective analysis of a longitudinal cohort of employees from a multinational Fortune 100 financial services corporation based in the United States. This

\footnotetext{
${ }^{1}$ University of Illinois at Chicago, Chicago, Illinois.

${ }^{2}$ American Express Company, New York, New York.

${ }^{3}$ University of Michigan Health Management Research Center, Ann Arbor, Michigan.
} 
corporation has approximately 26,000 employees at multiple sites in the United States.

The corporation has a global well-being program that features best-in-class resources, enhanced access to care, and a supportive work environment. The program goals are to improve employee health and business productivity/performance, and to control long-term health and productivity costs.

Approximately $65 \%$ of this corporation's employees selfreported at least 1 chronic health condition on their 2013 health risk appraisal (HRA). Approximately 5\% of employees reported having diabetes on the 2013 HRA. In 2012, medical and pharmacy costs for an employee with diabetes were $\$ 9340$ in contrast to $\$ 4447$ for an employee without diabetes. There were additional costs related to absenteeism, disability, and decreased on-the-job productivity (presenteeism) for the population with diabetes.

There are many barriers to chronic health condition management for employees. They include: provider lack of time, lack of qualified health education providers in health care provider offices, poor implementation of disease management guidelines by health providers, fragmentation of the health care system, and lack of reimbursement benefits for health education.

In an effort to eliminate those barriers, the corporation launched the Healthy Living with Diabetes program in 2012. The goals of the program were to:

- Educate employees on the value and importance of diabetes management

- Provide employees with information to enhance diabetes self-care

- Provide a systematic approach to improving diabetes outcomes

- Develop sustainable engagement in the employee's management of diabetes

In 2012, the Healthy Living with Diabetes program was offered at all 6 worksite Health and Wellness Centers ("worksite clinics") across the United States. The on-site health clinics serve between 400 and 4000 employees and reach approximately $50 \%$ of the total US employee population of this corporation. Depending on the size of the employee population, these clinics are staffed by physicians/ nurse practitioners, occupational health nurses, a health coach, and/or a dietitian, and an employee assistance program (EAP) counselor. A communication plan was developed for the Healthy Living with Diabetes disease management program that consisted of creative logos and taglines used to invite employees with diabetes and prediabetes to opt into the program. Graphics including gummy bears and the tagline, It's not just about the sugar, were used as a friendly, nonthreatening approach to diabetes management. Communications were posted on the company's intranet, and flyers and posters advertising the program were placed in all the Health and Wellness Centers and other public areas. There was no targeted mailing or identification of employees with diabetes based on a questionnaire or health screening other than some tailored communications to populations at increased risk for diabetes, including African Americans and Hispanics, which were sent through a partnership with employee diversity networking groups.

Various incentives were offered for program participation. For example, employees received a backpack with diabetes educational materials and a free glucometer (One
Touch Ultra and One Touch Mini; Lifescan, Inc., a Johnson \& Johnson company, Milpitas, CA) with a starter supply of glucose test strips, no-cost biometric screenings, wellness raffles, \$25 debit cards for completing 6-month and 12month biometric testing, and access to a comprehensive range of resources to meet the program goals.

Participants were self-selected members of the employee wellness center and were recruited through wellness center flyers, posters, and internal advertising (ie, staff, E-posters, Web site), and at screenings. Employees with both type 1 and type 2 DM, those at risk for diabetes, and employees with prediabetes were encouraged to enroll in this program. Participants completed a registration questionnaire and baseline biometric screenings. The questionnaire included a brief medical history including questions about current treatment of their diabetes and behavioral health questions including the Patient Health Questionnaire 2 (PHQ-2) depression screener. ${ }^{16}$ Biometric screening included measurements of blood pressure; height, weight, and waist circumference measurements; fasting venous blood specimens for lipid levels (total cholesterol, highdensity lipoprotein cholesterol, calculated low-density lipoprotein (LDL) cholesterol, and triglycerides), blood glucose, and hemoglobin A1c (HbA1c). Follow-up biometric screenings were offered at 6 months into the program and at the conclusion of this 12-month program. Participants also were asked to complete the post-program questionnaire at the end of the program. The post-program questionnaire asked the same questions as the preprogram questionnaire, with additional questions related to program evaluation. Of the initial 250 employees who signed up for the program, 230 completed the preregistration survey, 196 participated in at least 1 biometric screening, and 101 employees completed both the preprogram and post-program surveys. Among those who completed both surveys, 69 also completed all 3 laboratory tests at baseline, 6 months, and 12 months. This study is focused on those 101 participants who answered both preprogram and post-program questionnaires.

During the program year, participants had access at no cost to a multidisciplinary team of worksite clinic staff for one-on-one consultations. The team includes a registered nurse or nurse practitioner, health coach, dietitian, pharmacist, and EAP counselor. Group classes were presented by a certified diabetic health educator, dietitian, and consulting pharmacist from the corporation's Pharmacy Benefit Manager. An EAP counselor was available in each worksite clinic and behavioral health education also was available via webinars, which were recorded and available for later replay. Topics covered in group classes or webinar series included: What is Diabetes, Carbohydrate Counting and Maintaining a Healthy Diet, Exercise and Diabetes, Diabetes Medication Management, and Dealing with a Chronic Condition at Work and Home. To keep participants engaged, technology tools, including educational e-mails with Web site links, were used as touch points every 2 weeks, along with prize raffles for participation in group classes or webinar presentations.

\section{Results}

\section{Demographics}

Demographics and diabetes status of the study participants are presented in Table 1. A total of 101 employees participated in the program and completed preprogram and 
Table 1. Demographics and Diabetes Status of Study Participants at Baseline

\begin{tabular}{|c|c|c|c|c|}
\hline & \multicolumn{2}{|c|}{$\begin{array}{l}\text { Participants } \\
\text { of both pre } \\
\text { and post } \\
\text { surveys }\end{array}$} & \multicolumn{2}{|c|}{$\begin{array}{c}\text { Also participated } \\
\text { all } 3 \text { biometric } \\
\text { screenings }\end{array}$} \\
\hline & $\mathrm{n}=101$ & $\%$ & $\mathrm{n}=69$ & $\%$ \\
\hline Average Age & \multicolumn{2}{|c|}{49.0 years } & \multicolumn{2}{|c|}{48.8 years } \\
\hline \multicolumn{5}{|l|}{ Sex } \\
\hline Male & 31 & $30.7 \%$ & 22 & $31.9 \%$ \\
\hline Female & 70 & $69.3 \%$ & 47 & $68.1 \%$ \\
\hline \multicolumn{5}{|l|}{ Location* } \\
\hline Arizona & 38 & $37.6 \%$ & 29 & $42.0 \%$ \\
\hline Utah & 11 & $10.9 \%$ & 6 & $8.7 \%$ \\
\hline Florida & 36 & $35.6 \%$ & 18 & $26.1 \%$ \\
\hline New York & 16 & $15.8 \%$ & 16 & $23.2 \%$ \\
\hline \multicolumn{5}{|l|}{ Work remotely* } \\
\hline All of the time & 12 & $11.9 \%$ & 5 & $7.3 \%$ \\
\hline Some of the time & 40 & $39.6 \%$ & 29 & $42.0 \%$ \\
\hline Never & 49 & $48.5 \%$ & 35 & $50.7 \%$ \\
\hline \multicolumn{5}{|l|}{ Ethnicity } \\
\hline White & 52 & $51.5 \%$ & 35 & $50.7 \%$ \\
\hline Black & 16 & $15.8 \%$ & 10 & $14.5 \%$ \\
\hline $\begin{array}{l}\text { Asian or Pacific } \\
\text { Islander }\end{array}$ & 13 & $12.9 \%$ & 11 & $15.9 \%$ \\
\hline Hispanic & 10 & $9.9 \%$ & 6 & $8.7 \%$ \\
\hline Other/No response & 10 & $9.9 \%$ & 7 & $10.2 \%$ \\
\hline \multicolumn{5}{|c|}{ Has your doctor told you that you have...* } \\
\hline Diabetes & 65 & $64.4 \%$ & 40 & $58.0 \%$ \\
\hline Prediabetes & 21 & $20.8 \%$ & 17 & $24.6 \%$ \\
\hline $\begin{array}{l}\text { Elevated blood } \\
\text { glucose }\end{array}$ & 4 & $4.0 \%$ & 4 & $5.8 \%$ \\
\hline $\begin{array}{l}\text { Increased risk factors } \\
\text { for diabetes }\end{array}$ & 9 & $8.9 \%$ & 7 & $10.1 \%$ \\
\hline None of the Above & 2 & $2.0 \%$ & 1 & $1.5 \%$ \\
\hline \multicolumn{5}{|c|}{ How long have you had diabetes?* } \\
\hline $\begin{array}{c}\text { No diabetes or } \\
\text { prediabetes }\end{array}$ & 31 & $30.7 \%$ & 24 & $34.8 \%$ \\
\hline $1-12$ months & 9 & $8.9 \%$ & 5 & $7.3 \%$ \\
\hline 13-60 months & 27 & $26.7 \%$ & 15 & $21.7 \%$ \\
\hline $6-10$ years & 23 & $22.8 \%$ & 19 & $27.5 \%$ \\
\hline 11 years or longer & 11 & $10.9 \%$ & 6 & $8.7 \%$ \\
\hline \multicolumn{5}{|c|}{ Who currently provides your main diabetes care? } \\
\hline Generalist & 60 & $59.4 \%$ & 39 & $56.2 \%$ \\
\hline Specialist & 19 & $18.8 \%$ & 15 & $21.7 \%$ \\
\hline Other & 5 & $5.0 \%$ & 3 & $4.5 \%$ \\
\hline $\begin{array}{l}\text { No one or not } \\
\text { applicable }\end{array}$ & 17 & $16.8 \%$ & 12 & $17.4 \%$ \\
\hline
\end{tabular}

$* P<0.05$, McNemar's Test, compared to overall participants population.

post-program questionnaires in the Diabetes Education Program (Table 1).

After the program, more participants were under the care of a health care provider, with the "no provider" response declining from $16.8 \%$ to $10.9 \%$ and a corresponding increase in care by a generalist or specialist and a decline in care by "other" provider.

\section{Biometric testing}

Although follow-up biometric tests were offered to all participants, not everyone completed all 3 tests. Of the 101 who completed both surveys, 69 participated in all 3 biometric screenings at baseline, 6 months, and 12 months. Table 1 shows these 3-time screening participants were similar to the survey completers in terms of sex, age, and ethnicity. Work location and remote working status did influence the screening participation.

Among the 65 diabetic employees, 40 (61.5\%) completed all 3 biometrics screenings. Among the 34 employees who had prediabetes or were at risk for diabetes, $28(82.4 \%)$ completed all 3 biometric tests at baseline, 6 months, and 12 months. Table 2 shows both the test values and percentage of people who reached various biometric goals set by the American Diabetes Association ${ }^{17}$ for those with prediabetes or found to be at high risk for diabetes on the preprogram survey. Table 3 shows the same information for employees who had diabetes on the preprogram survey. What is evident from the baseline testing in both groups is how well, in general, they remain in good control of their DM. Although the observed changes did not reach statistical significance, all measured items showed either maintenance or slight improvement.

The mean HbA1c level of employees with diabetes was $7.2 \%$ at baseline, $7.2 \%$ at 6 months, and $7.3 \%$ at 12 months (Table 3). Mean LDL-cholesterol levels were all within the normal limits. Only the mean body mass index was abnormal at baseline, 6 months, and 12 months.

Among employees classified as having prediabetes or being at high risk for diabetes, the mean HbAlc, systolic and diastolic blood pressure, and lipid levels were, on average, normal. The percentage of participants with an HbA1c $<7 \%$ declined from $96.4 \%$ at baseline and 6 months to $85.7 \%$ at 12 months.

\section{Knowledge of diabetes}

Questions were asked at pre program and post program to determine participant knowledge of diabetes and its management (Fig. 1). Overall self-reported understanding of diabetes care increased (good, very good, or excellent) significantly from $70.3 \%$ to $94.1 \%(P<0.0001)$. Ability to cope with stress increased from $69.3 \%$ to $84.2 \%$ $(P=0.0035)$, knowledge of the understanding of diet for blood sugar control increased from $70.3 \%$ to $82.2 \%$ $(P=0.0455)$, the role and importance of exercise in diabetes care increased from $73.3 \%$ to $89.1 \%(P=0.0007)$, and understanding of diabetes medications increased from $69.3 \%$ to $92.1 \%(P=0.0002)$. Understanding of blood glucose monitoring increased from $66.3 \%$ to $90.1 \%(P<0.0001)$, and understanding of how diet, exercise, and medications affect blood glucose levels increased from $73.3 \%$ to $91.1 \%$ $(P=0.0002)$. Similarly there was a statistically significant increase in knowledge of the prevention and treatment of high blood glucose $(P<0.0001)$, low blood glucose $(P<0.0001)$, prevention of long-term complications of diabetes $(P<0.0001)$, foot care $(P<0.0001)$, and benefits of improving blood glucose control $(P<0.0001)$.

\section{Diabetes care}

In contrast to the statistically significant changes in the knowledge of diabetes, there were generally no statistically significant changes in diabetes biometrics and control. These results are summarized in Figure 2. Participants 
Table 2. Pre- and Post-Program Survey Participants with Baseline, 6-Month, and 12-Month Biometrics Measures: Prediabetes/At Risk for Diabetes

\begin{tabular}{|c|c|c|c|c|c|c|c|}
\hline & \multicolumn{7}{|c|}{$\begin{array}{c}\text { Prediabetes/At Risk for Diabetes at Baseline }(n=28 \text { out } \\
\text { of } 34 \text { with prediabetes or at risk at baseline })\end{array}$} \\
\hline & \multicolumn{3}{|c|}{ Means } & \multirow[b]{2}{*}{ Goal $^{17}$} & \multicolumn{3}{|c|}{$\%$ Reached Goals } \\
\hline & Baseline & 6 months & 12 months & & Baseline & 6 months & 12 months \\
\hline Glucose (mg/dL) & 104.4 & 103.7 & 105.3 & $\leq 100 \mathrm{mg} / \mathrm{dL}$ & $53.6 \%$ & $46.4 \%$ & $50.0 \%$ \\
\hline $\operatorname{HbA1c}(\%)$ & 6.0 & 5.9 & 5.9 & $<7.0 \%$ & $96.4 \%$ & $96.4 \%$ & $85.7 \%$ \\
\hline SBP (mmHg) & 121.1 & 120.3 & 122.9 & $140 / 90 \mathrm{mmHg}$ & $78.6 \%$ & $85.7 \%$ & $75.0 \%$ \\
\hline $\mathrm{DBP}(\mathrm{mmHg})$ & 80.9 & 79.5 & 77.4 & & & & \\
\hline Total Cholesterol (mg/dL) & 177.0 & 175.0 & 176.2 & $<200 \mathrm{mg} / \mathrm{dL}$ & $78.6 \%$ & $82.1 \%$ & $78.6 \%$ \\
\hline LDL (mg/dL) & 101.3 & 101.6 & 98.5 & $<100 \mathrm{mg} / \mathrm{dL}$ & $50.0 \%$ & $53.6 \%$ & $57.1 \%$ \\
\hline HDL (mg/dL) & 46.7 & 47.0 & 50.3 & $\mathrm{M},>40 \mathrm{mg} / \mathrm{dL} \mathrm{F},>50 \mathrm{mg} / \mathrm{dL}$ & $42.9 \%$ & $57.1 \%$ & $53.6 \%$ \\
\hline Triglycerides (mg/dL) & 145.3 & 131.9 & 137.0 & $<150 \mathrm{mg} / \mathrm{dL}$ & $64.3 \%$ & $71.4 \%$ & $64.3 \%$ \\
\hline Weight (lbs) & 204.4 & 204.3 & 203.1 & & & & \\
\hline $\operatorname{BMI}\left(\mathrm{kg} / \mathrm{m}^{2}\right)$ & 32.1 & 32.6 & 32.2 & $<30 \mathrm{~kg} / \mathrm{m}^{2}$ & $42.9 \%$ & $39.3 \%$ & $39.3 \%$ \\
\hline Waist Circumference (in) & 40.1 & 39.9 & 40.5 & $\mathrm{M}, \leq 40$ inches $\mathrm{F}, \leq 35$ inches & $35.7 \%$ & $35.7 \%$ & $35.7 \%$ \\
\hline
\end{tabular}

BMI, body mass index; DBP, diastolic blood pressure; F, female; HDL, high-density lipoprotein cholesterol; in, inches; LDL, low-density lipoprotein cholesterol; M, male; SBP, systolic blood pressure.

generally report increased blood glucose testing $(P=$ $0.0105)$; however there was no significant change in the number of times they experienced either low or high blood glucose in the past month. Although the percentage of employees reporting exercising 3 or more times per week increased from $44.6 \%$ to $53.5 \%$, the increase was not statistically significant $(P=0.1282)$. Fewer participants reported that diabetes kept them from normal activities, although the difference was not statistically significant. Fewer participants reported that paying for diabetes treatment was a problem and decreased at baseline from $72.3 \%$ to $57.4 \%$ at 12 months $(P=0.0122)$.

Instructed to have following a meal plan both statistically improved from pre program to post program $(P=0.0004$ and $P=0.0027$, respectively) (Fig. 2). Participants were more likely to perform a foot examination regularly after the program, $63.4 \%$ vs. $79.2 \%(P=0.0017)$.
There was no significant change in the last time participants had HbA1c or cholesterol testing; however almost $90 \%$ of participants report having these tests in the past 6 months. It is important to note that several participants had prediabetes or were at risk for diabetes, in which case laboratory tests generally are not routinely indicated every 6 months. There was no significant change in the use of medications including insulin or in reported complications of diabetes such as hypertension and cardiovascular disease from baseline to 12 months.

\section{Diabetes and self-reported outcomes}

Preprogram general health was described as good, very good, or excellent by $79.2 \%$ of participants at baseline and by $85.1 \%(P=0.0833)$ at post program, which is considered borderline statistically significant.

Table 3. Pre- and Post-Program Survey Participants with Baseline, 6-Month, and 12-Month Biometric Measures: With Diabetes

\begin{tabular}{|c|c|c|c|c|c|c|c|}
\hline & \multicolumn{7}{|c|}{ Diabetes at Baseline ( $n=40$ out of 65 people with diabetes at baseline) } \\
\hline & \multicolumn{3}{|c|}{ Means } & \multirow[b]{2}{*}{ Goal $^{17}$} & \multicolumn{3}{|c|}{$\%$ Reached Goals } \\
\hline & Baseline & 6 months & 12 months & & Baseline & 6 months & 12 months \\
\hline Glucose (mg/dL) & 140.5 & 146.9 & 152.6 & $\leq 100 \mathrm{mg} / \mathrm{dL}$ & $17.5 \%$ & $17.5 \%$ & $12.5 \%$ \\
\hline $\mathrm{HbA} 1 \mathrm{c}(\%)$ & 7.2 & 7.2 & 7.3 & $<7.0 \%$ & $60.0 \%$ & $65.0 \%$ & $47.5 \%$ \\
\hline $\mathrm{SBP}(\mathrm{mmHg})$ & 131.7 & 130.5 & 130.9 & $140 / 90 \mathrm{mmHg}$ & $65.0 \%$ & $60.0 \%$ & $57.5 \%$ \\
\hline DBP (mmHg) & 83.5 & 80.6 & 81.4 & & & & \\
\hline Total Cholesterol (mg/dL) & 171.8 & 172.5 & 169.2 & $<200 \mathrm{mg} / \mathrm{dL}$ & $90.0 \%$ & $80.0 \%$ & $80.0 \%$ \\
\hline LDL (mg/dL) & 90.0 & 94.5 & 88.8 & $<100 \mathrm{mg} / \mathrm{dL}$ & $67.5 \%$ & $60.0 \%$ & $67.5 \%$ \\
\hline HDL (mg/dL) & 47.1 & 47.3 & 48.7 & $\mathrm{M},>40 \mathrm{mg} / \mathrm{dL} \mathrm{F},>50 \mathrm{mg} / \mathrm{dL}$ & $52.5 \%$ & $45.0 \%$ & $55.0 \%$ \\
\hline Triglycerides (mg/dL) & 169.9 & 159.1 & 162.0 & $<150 \mathrm{mg} / \mathrm{dL}$ & $62.5 \%$ & $60.0 \%$ & $55.0 \%$ \\
\hline Weight (lbs) & 207.4 & 211.1 & 208.5 & & & & \\
\hline BMI $\left(\mathrm{kg} / \mathrm{m}^{2}\right)$ & 34.4 & 34.8 & 34.3 & $<30 \mathrm{~kg} / \mathrm{m}^{2}$ & $30.0 \%$ & $25.0 \%$ & $30.0 \%$ \\
\hline Waist Circumference (in) & 42.4 & 43.3 & 43.0 & $\mathrm{M}, \leq 40$ inches $\mathrm{F}, \leq 35$ inches & $22.5 \%$ & $17.5 \%$ & $25.0 \%$ \\
\hline
\end{tabular}

BMI, body mass index; DBP, diastolic blood pressure; F, female; HDL, high-density lipoprotein cholesterol; in, inches; LDL, low-density lipoprotein cholesterol; M, male; SBP, systolic blood pressure. 


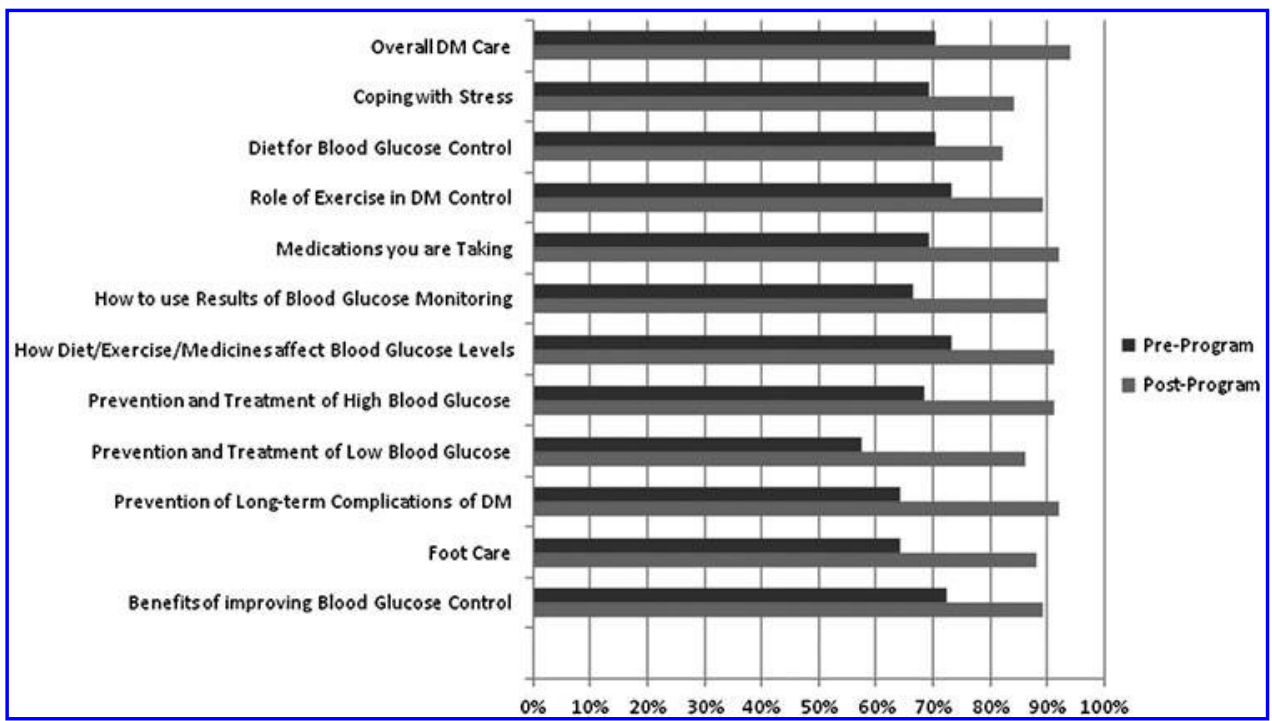

FIG. 1. Knowledge of diabetes mellitus (DM) at pre program and 12-month follow-up (percentage responding excellent, very good, or good) $(\mathrm{N}=101)$.

Depression is a known comorbidity with diabetes and was assessed at baseline and 12-month follow-up with the PHQ$2^{18,19,20}$ The PHQ-2 score declined by 0.29 points on average from 1.0792 to $0.7980(P=0.0592)$; however, the percent of participants with depression (PHQ-2 score greater than or equal to 3 ) declined from $14.9 \%$ to $9.9 \%$, which was directionally important, but not statistically significant $(P=0.1967)$ (Fig. 3).

Worker productivity ("presenteeism") was assessed with the 8-question Work Limitation Questionnaire. In this study, 3 domains (time management, interpersonal, and output) were assessed with this questionnaire. Only the output domain change was statistically significant $(P=0.0412)$. There was no change in the self-reported number of days missed from work in the past 6 months related to diabetes.

\section{Program attendance and evaluation}

Almost all participants found this educational program to be very helpful in imparting knowledge about their disease. Participant responses were as follows: extremely helpful (48.5\%), very helpful (36.6\%), somewhat helpful (13.9\%); only 1 respondent reported that it was "not very helpful or valuable" (1.0\%). Attendance at at least 1 of the additional sessions was reported by $82.2 \%$ of participants and participants attended an average of 2.7 additional sessions. The

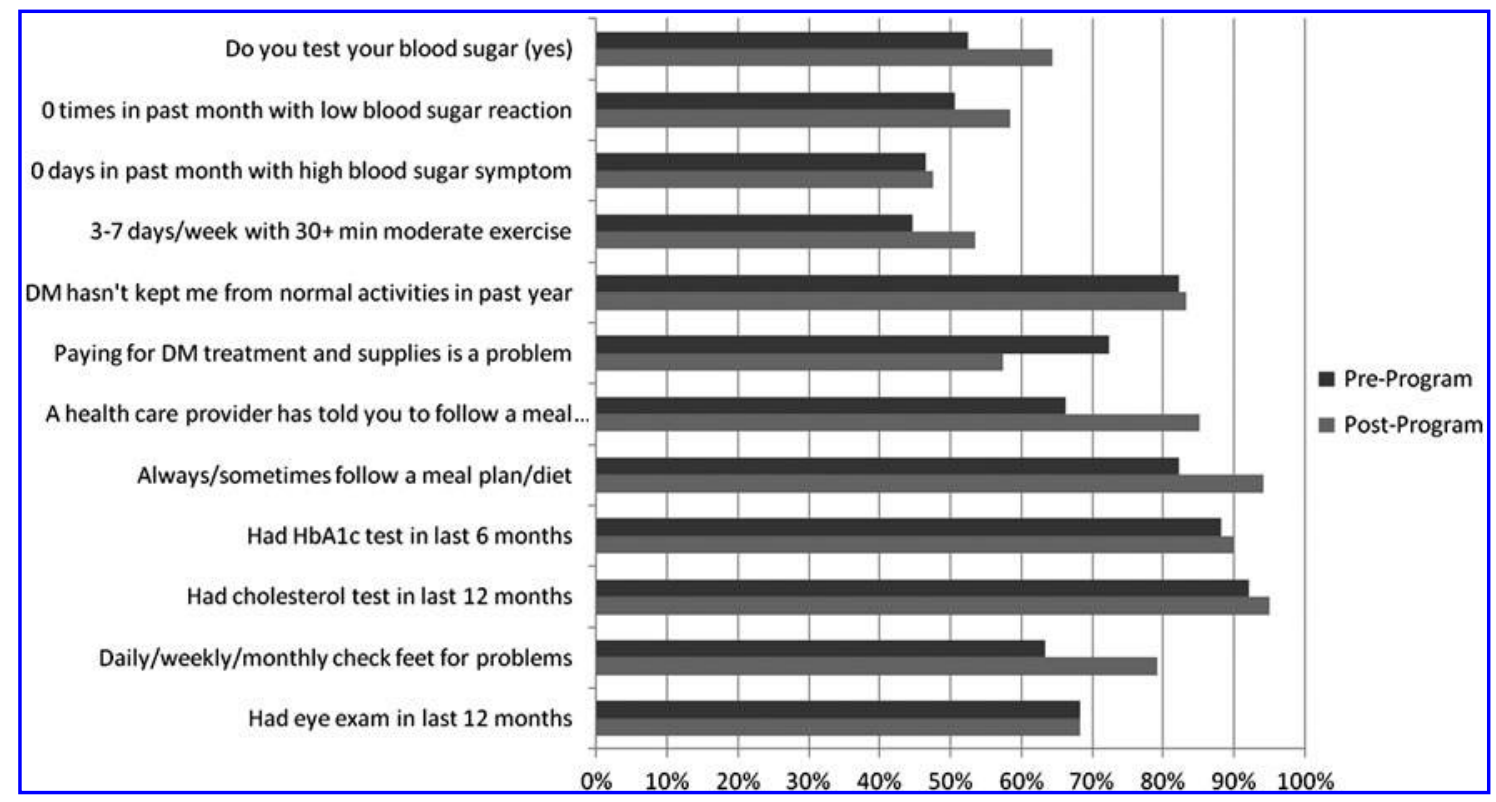

FIG. 2. Diabetes care actions at pre program and 12-month follow-up $(\mathrm{N}=101)$. DM, diabetes mellitus. 


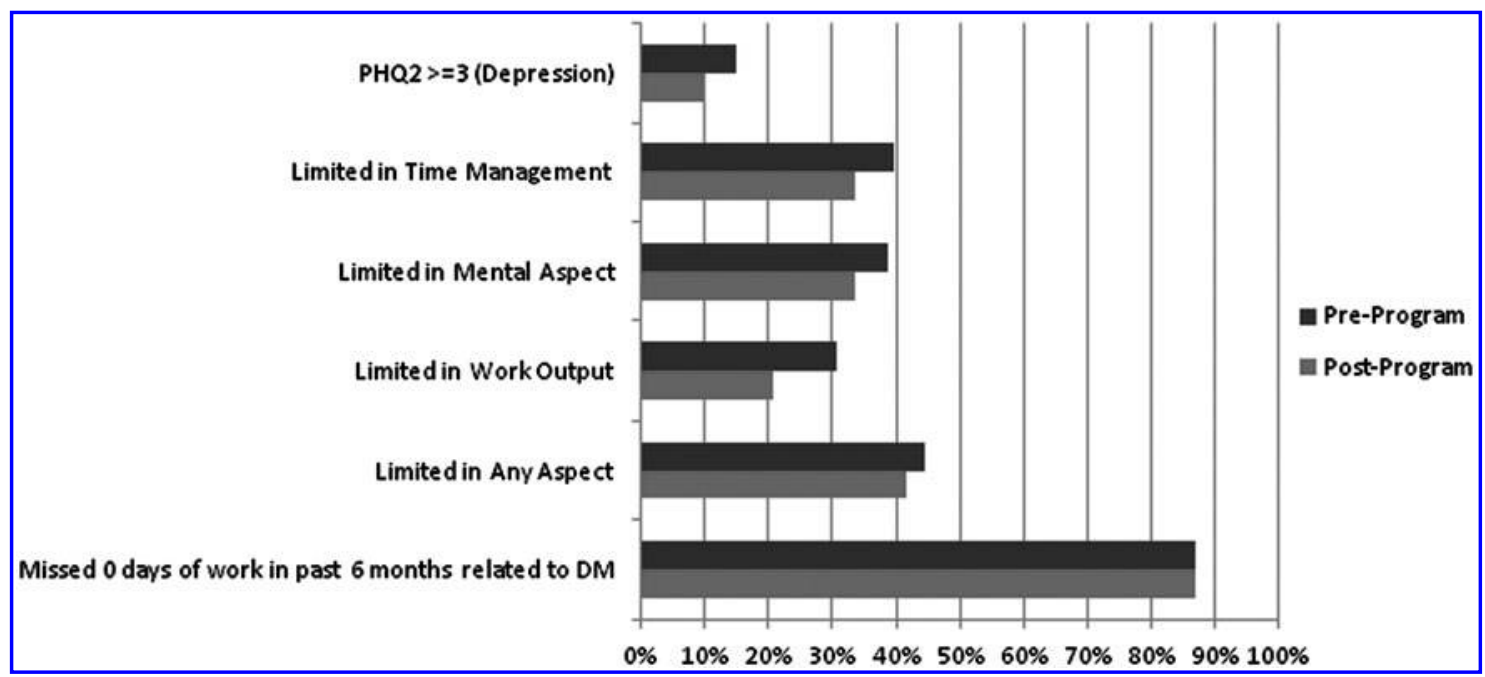

FIG. 3. Diabetes and work-related outcomes $(\mathrm{N}=101)$. PHQ-2, Patient Health Questionnaire-2.

vast majority of participants worked with a member of the on-site clinical care team including a nurse or nurse practitioner $(88.1 \%)$, health coach $(55.4 \%)$, registered dietitian $(72.3 \%)$, pharmacist $(23.8 \%)$, and/or EAP counselor $(7.9 \%)$.

\section{Changes made associated with the program}

Diabetics reported the following actions: saw a doctor $(31.7 \%)$; started on medication $(5.9 \%)$; medication changed by their doctor (15.8\%); started an exercise program $(53.5 \%)$; lost weight (47.5\%); quit or attempted to quit smoking (4\%), which was among all reported smokers; talked to an EAP counselor $(5.9 \%)$; other $(7.9 \%)$.

\section{Discussion}

It should be anticipated that patients with diabetes who received education and counseling would be more likely to have improved glycemic, blood pressure, and hyperlipidemia control. However, studies have shown that patients in general are not receiving the education and counseling they need. This study evaluated the role a worksite diabetes disease management program integrated with a workplace occupational health clinic medical team had on biometrics and disease knowledge for an employee population who was at risk for diabetes, had prediabetes, or was diagnosed with diabetes.

This study demonstrated significant improvement in employee knowledge of diabetes. However, biometrics in general did not show a significant change in part because diabetes was already relatively well controlled in this insured employee population. Diabetic participants had a mean baseline HbA1c level of $7.2 \%$ and generally wellcontrolled blood pressure and blood lipid levels. The valuebased insurance design in a full replacement ConsumerDirected Health Plan offered by this employer probably contributed to these findings. Preventive care, including annual physicals, were covered at $100 \%$ with no deductible or co-payments. Generic prescription oral diabetes medications were available "free" to employees with no co-payments or insurance deductible.
There have been relatively few long-term studies evaluating the effectiveness of diabetes self-management education programs and the outcomes of these studies have reported mixed results. Deakin et al reviewed a group-based patient training of self-management strategies in type 2 diabetes and found they were effective in improving blood glucose, blood pressure, body weight, and the need for antidiabetic drugs. ${ }^{21,22}$ Khunti et al reported on a 3-year follow-up of an education and self-management program for people newly diagnosed with type 2 diabetes. ${ }^{23}$ This study was conducted in 13 primary care sites in the United Kingdom. The primary outcome was HbAlc levels. The secondary outcomes included blood pressure, weight, blood lipid levels, smoking status, physical activity, quality of life, beliefs about illness, depression, emotional impact of diabetes, and drug use at 3 years. There was no statistically significant difference at 3 years in HbA1c levels between the intervention and nonintervention groups. Neither was there a difference in other biometrics, lifestyle, depression, quality of life, and drug use outcomes. However, the authors found a significant improvement in 4 of 5 health beliefs at 3 years. The intervention group had a greater understanding of their illness and its seriousness and a better understanding of their ability to affect the course of their disease. SperlHillen et al reported that individual health education and not a group health education program for patients with suboptimally controlled diabetes resulted in better glycemic control. $^{24}$

Morrison et al reported on a retrospective analysis of 26,496 patients with diabetes and elevated HbA1c, blood pressure, and/or LDL cholesterol treated by primary care physicians at 2 teaching hospitals. Patients who saw their primary care physician every 2 weeks achieved HbA1c, blood pressure, and LDL cholesterol targets the fastest. ${ }^{25,26}$

Rasekba et al reported on the results of a diabetes disease management program on diabetes control and patient quality of life in 967 patients and 12-month follow-up in Australia. Baseline HbA1c was $8.6 \%$ and was $7.3 \%$ at 12 months. However, patients with diabetes in their study population were, in general, not well controlled in contrast to the 
present study's employee patient population, which had good overall HbA1c control on average. ${ }^{27}$

There are a variety of reasons why patients with diabetes are noncompliant, including nonadherence to medications. Noncompliance could be because patients with diabetes also may suffer from depression. ${ }^{28}$ Gonzalez et al reported that $19 \%$ of patients with type 2 diabetes probably suffered from major depression and an additional 66\% reported some symptoms of depression. ${ }^{29}$ Patients with depression were less adherent to diet, exercise, glucose self-monitoring and medication adherence. Because depression and depressive symptoms are associated with nonadherence, participants in the present study were provided with both written materials on depression and offered a webinar presented by a clinical psychologist who is director of the firm's EAP. Visits with an EAP counselor were available at no cost to the employee in each of the worksite occupational health clinics. Employees also can see an EAP provider in the community at no cost for up to 8 visits.

Previous studies have examined the potential association between reduced patient cost sharing with a value-based benefit design and increased medication adherence in patients with diabetes. ${ }^{30,31,32}$ To address this concern, the corporation initiated a value-based pharmacy benefit design that provided free generic preventive medications for diabetes, hypertension, and hyperlipidemia. Insulin also was added to the free preventive medication benefit. It is anticipated that increased diabetes medication adherence would result in decreased emergency department visits and hospitalizations, less absenteeism and disability, and increased on-the-job productivity related to better diabetes control. The employee survey did find that the cost of diabetes supplies for glucose self-monitoring may be a barrier to glycemic control, indicating a benefit design issue that will need to be addressed.

Researchers have examined other factors related to control of diabetes. For example, Jameson et al reported on the benefit of including a pharmacist in the management of diabetes. ${ }^{33} \mathrm{~A}$ pharmacist was a member of the present study's intervention team and employees had access to individual consultations with the pharmacist at no cost. Graco et al failed to find an association between baseline psychological measures and glycemic control in diabetes. In a study of 86 patients with type 2 diabetes with an average baseline $\mathrm{HbA} 1 \mathrm{c}$ of $8.9 \%$ indicating poor control, improved control was associated with being seen earlier in their disease course and more intense management regardless of their psychometric status. ${ }^{34}$

\section{Limitations}

The study team acknowledges certain limitations that are present in most worksite applied research studies. This was not a randomized controlled study. Therefore, employees who enrolled and completed the program may not represent the entire population with diabetes for this employer. Their diabetes may or may not be controlled to the same extent as the entire employee population. This population may be more motivated to control their diabetes than the general diabetes population for the employer. Biometric testing indicated that, on average, the diabetes in this study population was controlled. It is unknown if this educational model can be extrapolated to other employers with different types of jobs, employee education level, or employee demographics. Longer term follow-up of this population is needed to determine if the educational intervention learning is sustainable.

The 12-month completion rate of this program was $40 \%$ for those participants who completed the preprogram questionnaire. There were several reasons for dropout, including 36 individuals who were no longer employed by the conclusion of the program, and others who chose to discontinue their participation. For the 92 employees who completed the preprogram questionnaire but not the post-program questionnaire, their results indicate they had poorer control of their diabetes than those who fully completed the program; 28 of those 92 employees participated in all 3 biometric screenings, even though they did not complete the postprogram questionnaire. Biometric measurements for this group showed mixed results with improvement in some measures and maintenance in others. The research team is unable to explain why employees who participated in the majority of the program activities chose not to complete the post-program questionnaire, and become eligible for a prize raffle of an e-reader/tablet device. However, poor completion rates are a commonly reported problem in disease management programs. ${ }^{35}$ Another challenge in this organization and many others is how to reach employees who work remotely with programs such as these.

\section{Conclusions}

A 12-month worksite-based educational program for employees who were at risk for diabetes, had prediabetes, or were diagnosed with diabetes statistically improved most selfefficacy measures. However, this population generally had acceptable control of their diabetes and there was no statistically significant improvement in biometric tests at 6 and 12 months. Worksite occupational medicine clinics staffed by health professionals including a physician/nurse practitioner, nurse, health coaches, dietician, consulting pharmacist, and EAP counselor offer an important service in assisting employees with a variety of chronic diseases such as DM.

\section{Acknowledgment}

The authors thank Novo Nordisk for diabetic health educators and diabetic health education materials to support this program.

\section{Author Disclosure Statement}

Drs. Burton, Chen, and Schultz, and Mr. Li, Ms. Erickson, Ms. McCluskey declared no conflicts of interest with respect to the research, authorship, and/or publication of this article. The authors received no financial support for the research, authorship, and/or publication of this article.

\section{References}

1. Centers for Disease Control and Prevention. National Diabetes Fact Sheet: National Estimates and General Information on Diabetes and Prediabetes in the United States, 2011. Atlanta, GA: Centers for Disease Control and Prevention; 2011.

2. Dall TM, Zhang V, Chen YJ, Quick WW, Yang WG, Fogli J. The economic burden of diabetes. Health Aff (Millwood). 2010:29;297-303. 
3. Seaquist ER. Addressing the burden of diabetes. JAMA. 2014;311:2267-2268.

4. Rowley WR, Bezold C. Creating public awareness: State 2015 Diabetes Forecasts. Popul Health Manag. 2012;15: 194-2000.

5. Geiss LS, Wang J, Cheng YJ, et al. Prevalence and incidence trends for diagnosed diabetes among adults aged 20 to 79 years, United States, 1980-2012. JAMA. 2014;312:1218-1226.

6. McLellan RK, Sherman B, Loeppke RR, et al. Optimizing health care delivery by integrating workplaces, homes and communities: how occupational and environmental medicine can serve as a vital connecting link between accountable care organizations and the patient-centered medical home. J Occup Environ Med. 2012;54:504-512.

7. Sherman BW, Fabius RJ. Quantifying the value of worksite clinic nonoccupational health care services. J Occup Environ Med. 2012;54:394-403.

8. Li G, Zhang P, Wang J, et al. The long-term effect of lifestyle interventions to prevent diabetes in the China Da Qing Diabetes Prevention Study: a 20-year follow-up study. Lancet. 2008;371:1783-1789.

9. Knowler WC, Barrett-Connor E, Fowler SE, et al. Reduction in the incidence of type 2 diabetes with lifestyle intervention or metformin. N Eng J Med. 2002;346:393-403.

10. The Look Ahead Research Group. Cardiovascular effects of intensive lifestyle intervention in type 2 diabetes. $\mathrm{N}$ Engl J Med. 2013;369:145-154.

11. Haas L, Maryniuk M, Beck J, et al. National standards for diabetes self-management education and support. Diabetes Care. 2012;35:2393-2401.

12. Siminerio LM, Piatt GA, Emerson S, et al. Deploying the chronic care model to implement and sustain diabetes selfmanagement and training programs. Diabetes Educ. 2006; 32: $253-260$.

13. Siminerio LM, Piatt G, Zgibor JC. Implementing the chronic care model for improvements in diabetes care and education in a rural primary care practice. Diabetes Educ. 2005;31:225-234.

14. Burton WN, Connerty CM. Evaluation of a worksite-based patient education intervention targeted at employees with diabetes mellitus. J Occup Environ Med. 1998;40:702-706.

15. Burton WN, Connerty CM. Worksite-based diabetes disease management program. Dis Manag. 2002;5:1-8.

16. Kroenke K, Spitzer RL, Williams JB. The Patient Health Questionnaire-2: validity of a two-item depression screener. Med Care. 2003;41:1284-1292.

17. American Diabetes Association. Clinical Practice Recommendations. Diabetes Care. 2013;36(suppl 1):S4-S10.

18. Katon WJ. The comorbidity of diabetes mellitus and depression. Am J Med. 2008;121(11 suppl 2):S8-S15.

19. Musselman DL, Betan E, Larsen H, Phillips LS. Relationship of depression to diabetes types 1 and 2: epidemiology, biology, and treatment. Biol Psychiatry. 2003;54: 317-329.

20. Anderson RJ, Freedland KE, Clouse RE, Lustman PJ. The prevalence of comorbid depression in adults with diabetes: a meta-analysis. Diabetes Care. 2001;24:1069-1078.

21. Deakin T, McShane CE, Cade JE, Williams RD. Group based training for self-management strategies in people with type 2 diabetes mellitus. Cochrane Database Syst Rev. 2009;(2): CD003417.
22. Snoek FJ. Self management education and good professional consultation skills for patients with diabetes. BMJ. 2012;344:e2673.

23. Khunti K, Gray LJ, Skinner $\mathrm{T}$ et al. Effectiveness of a diabetes education and self management programme (DESMOND) for 824 people with newly diagnosed type 2 diabetes mellitus: three year follow-up of a cluster randomized controlled trial in primary care. BMJ. 2012; 344:e2333.

24. Sperl-Hillen J, Beaton S, Fernandes O, et al. Comparative effectiveness of patient education methods for type 2 diabetes: a randomized controlled trial. Arch Int Med. 2011;171: 2001-2010.

25. Morrison F, Shubina M, Turchin A. Encounter frequency and serum glucose level, blood pressure, and cholesterol level control in patients with diabetes mellitus. Arch Intern Med. 2011;171:1542-1550.

26. Goroll AH. When it comes to primary care, more may be more. Arch Intern Med. 2011;171:1550-1551.

27. Rasekaba TM, Graco M, Risteski C, et al. Impact of a diabetes disease management program on diabetes control and patient quality of life. Popul Health Manag. 2012;15: 12-19.

28. Ducat L, Phillipson LH, Anderson BJ. The mental health comorbidities of diabetes. JAMA. 2014; 312:691-692.

29. Gonzalez JS, Safren SA, Cagliero E, et al. Depression, selfcare and medication adherence in type 2 diabetes. Diabetes Care. 2007;30:2222-2227.

30. Gibson TB, Mahoney JJ, Lucase K, Heithoff K, Gatwood J. Value-based design and prescription drug utilization patterns among diabetes patients. Am J Pharm Benefits. 2013; 5:113-120.

31. Cheng SH, Chen CC, Tseng CH. Does medication adherence lead to lower healthcare expenses for patients with diabetes? Am J Manag Care. 2013;19:662-670.

32. Berger J. Economic and clinical impact of innovative pharmacy benefit designs in the management of diabetes pharmacotherapy. Am J Manag Care. 2007;13(suppl 2):S55-S58.

33. Jameson JP, Baty PJ. Pharmacist collaborative management of poorly controlled diabetes mellitus: a randomized controlled trial. Am J Manag Care. 2010;16:250-255.

34. Graco M, Hutchinson A, Barker A, Lawlor V, Fourlanos S. Glycemic outcome not predicted by baseline psychological measures in a diabetes management program. Popul Health Manag. 2012;15:163-167.

35. Thompson L. Disease management programs: improving health while reducing costs? Georgetown University Issue Briefs on Challenges for the 21st Century: Chronic and Disabling Conditions. Washington DC: Georgetown Health Policy Institute; 2004.

Address correspondence to: Wayne N. Burton, MD American Express Company 200 Vesey Street Mail Stop 01-35-08

New York, NY 10285-3805

E-mail: wayne.n.burton@aexp.com 
This article has been cited by:

1. Clayton R. Wilburn, David W. Bernard, Arthur W. Zieske, Julia Andrieni, Tara Miller, Ping Wang. 2017. The Prevalence and Role of Hemoglobin Variants in Biometric Screening of a Multiethnic Population. American Journal of Clinical Pathology 147:6, 589-595. [CrossRef]

2. Dina Hafez, Allison Fedewa, Margaret Moran, Matthew O’Brien, Ronald Ackermann, Jeffrey T. Kullgren. 2017. Workplace Interventions to Prevent Type 2 Diabetes Mellitus: a Narrative Review. Current Diabetes Reports 17:2. . [CrossRef] 